\title{
Association between inflammation and systolic blood pressure in RA compared to patients without RA
}

\author{
Zhi Yu ${ }^{1,2}$, Seoyoung C. Kim ${ }^{3,4}$, Kathleen Vanni ${ }^{3}$, Jie Huang ${ }^{3}$, Rishi Desai ${ }^{4}$, Shawn N. Murphy ${ }^{5,6,7}$,
}

Daniel H. Solomon ${ }^{3,4}$ and Katherine P. Liao ${ }^{3,7^{*}}$

\begin{abstract}
Background: The relationship between inflammation and blood pressure (BP) has been studied mainly in the general population. In this study, we examined the association between inflammation and BP across a broader range of inflammation observed in rheumatoid arthritis (RA) and non-RA outpatients.

Methods: We studied subjects from a tertiary care outpatient population with C-reactive protein (CRP) and BP measured on the same date in 2009-2010; RA outpatients were identified using a validated algorithm. General population data were obtained from the National Health and Nutrition Examination Survey (NHANES) as comparison. To study the cross-sectional association between CRP and BP in the three groups, we constructed a generalized additive model. Longitudinal association between CRP and BP was examined using a repeated-measures linear mixed-effects model in RA outpatients with significant change in inflammation at two consecutive time points.

Results: We studied 24,325 subjects from the outpatient population, of whom 1811 had RA, and 5561 were from NHANES. In RA outpatients, we observed a positive relationship between CRP and systolic BP (SBP) at CRP $<6 \mathrm{mg} / \mathrm{L}$ and an inverse association at CRP $\geq 6 \mathrm{mg} / \mathrm{L}$. A similar inverse U-shaped relationship was observed in non-RA outpatients. In NHANES, we observed a positive relationship between CRP and SBP as demonstrated by previous studies. Longitudinal analysis in RA showed that every $10 \mathrm{mg} / \mathrm{L}$ increase in CRP was associated with a $0.38 \mathrm{mmHg}$ reduction in SBP.

Conclusions: Across a broad range of CRP observed in RA and non-RA outpatients, we found an inverse U-shaped relationship between $\mathrm{CRP}$ and SBP, highlighting a relationship not previously observed when studying the general population.
\end{abstract}

Keywords: Inflammation, Blood pressure, Rheumatoid arthritis

\section{Background}

Inflammation is associated with elevated blood pressure (BP) in the general population [1, 2]. In rheumatoid arthritis (RA), the levels of inflammation, as measured by $\mathrm{C}$-reactive protein (CRP) can be 10-fold higher than in the general population. Whether the relationship between inflammation and BP remains the same under these

* Correspondence: kliao@bwh.harvard.edu

${ }^{3}$ Division of Rheumatology, Allergy and Immunology, Brigham and Women's Hospital, Boston, MA 02115, USA

${ }^{7}$ Department of Biomedical Informatics, Harvard Medical School, Boston, MA, USA

Full list of author information is available at the end of the article conditions has not been closely studied [3, 4]. Studying the association between inflammation and BP is particularly important in RA; cardiovascular (CV) risk is 1.5-2.0 times higher compared to individuals from the general population of similar age, sex, and CV risk factors [5-7]. This excess risk is attributed to inflammation [8].

There is also increasing evidence that inflammation may modify traditional risk factors such that higher levels of inflammation are associated with lower cholesterol levels [9-11]. However, these lower cholesterol levels are not associated with reduced CV risk; in RA, any given level of cholesterol may confer a higher $\mathrm{CV}$

(C) The Author(s). 2018 Open Access This article is distributed under the terms of the Creative Commons Attribution 4.0 International License (http://creativecommons.org/licenses/by/4.0/), which permits unrestricted use, distribution, and reproduction in any medium, provided you give appropriate credit to the original author(s) and the source, provide a link to the Creative Commons license, and indicate if changes were made. The Creative Commons Public Domain Dedication waiver (http://creativecommons.org/publicdomain/zero/1.0/) applies to the data made available in this article, unless otherwise stated. 
risk than expected based on general population-based studies due to the added effect of inflammation [10, 12]. Few studies have examined closely the relationship between inflammation and BP levels, and whether a similar modification may be occurring. Since both inflammation and BP are associated with an increased risk of cardiovascular disease (CVD) [13-16], understanding the relationship between the two can provide insight into pathways linking inflammation and CV risk not only in RA, but also in the general population.

The objective of this study was to examine the association between inflammation and BP in RA compared to a non-RA outpatient cohort, and a general population cohort. We hypothesize that the relationship between inflammation and BP may differ at the higher levels of inflammation observed in RA and other inflammatory conditions compared to levels observed in the general population.

\section{Methods \\ Study populations \\ General population cohort}

The National Health and Nutrition Examination Survey (NHANES) served as the general population control for this study [17]. The most recent NHANES data on CRP and BP spans from 1 January 2009 to 31 December 2010. Thus, this time frame was used to select data for all subjects in this study. Additionally, we studied only subjects aged 18 years or older.

\section{Outpatient population}

To obtain a broader range of CRP values, we examined the data on all outpatients followed at two large tertiary hospitals, Brigham and Women's Hospital (BWH) and Massachusetts General Hospital (MGH), Boston, MA, USA, with clinical data on approximately 7.2 million patients. BWH and MGH share one electronic medical record (EMR) system. The Partners Research Data Repository (RPDR) [18] enabled efficient extraction of de-identified clinical data across the two institutions. Using the same inclusion criteria applied to NHANES, the outpatient population consisted of adult patients aged 18 years and older, who had CRP and BP measured on the same day at an outpatient visit between 1 January 2009 and 31 December 2010. For the primary analysis we used the first same-day CRP and BP measurements of each subject. Inpatients were not included to reduce potential confounding from severe conditions such as sepsis.

\section{RA outpatient population and non-RA outpatient population}

We defined a subset of the outpatient population with a validated diagnosis of $\mathrm{RA}$, identified using a validated and published algorithm with a positive predictive value of $94 \%[19,20]$, as the RA outpatient population. For this cohort, we additionally extracted longitudinal data on subjects who had a change in CRP $\geq 10 \mathrm{mg} / \mathrm{L}$ between two time points and also had BP measurements at the two time points. We defined the rest of the outpatient population, subjects not diagnosed with RA, as the non-RA outpatient population.

\section{CRP and BP measurements}

In the NHANES cohort, CRP was measured using a high-sensitivity assay with latex-enhanced nephelometry [21]. Three consecutive BP measurements were obtained by certified examiners using a sphygmomanometer after participants had rested quietly while sitting for $5 \mathrm{~min}$ [22]. For the analysis, we only included subjects with valid $\mathrm{BP}$ readings for all three attempts. In the outpatient population, CRP was measured using the high-sensitivity CRP assay, performed in the clinical laboratories at Partners Healthcare using standardized methods [23]. BP is a required measurement at all outpatient visits at Partners Healthcare, obtained by trained healthcare providers, and entered as structured data into the EMR. BP values are recorded as systolic blood pressure (SBP) and diastolic blood pressure (DBP).

\section{Statistical analysis}

For the primary analysis, we focused on the association between CRP and SBP because it is the main target of BP intervention studies of CVD risk [13]. The CRP levels were common-log-transformed to normalize the distribution. Using graphical techniques, we visualized the relationship between CRP (common-log-transformed) and SBP in the RA outpatient population. From this graph, we observed that the relationship was non-linear. Thus, we constructed a generalized additive model with penalized splines as the approach to study the association between CRP and SBP, adjusting for age (continuous), gender, and race (non-Hispanic white/non-Hispanic black/other races); electronic prescription data were used to obtain information on anti-hypertensive medication, statins, methotrexate (MTX), and tumor necrosis factor inhibitors (TNFi), as a binary value for ever/ never use. Since we are interested in studying a nonlinear association between the variables, we applied the generalized additive model. This approach uses semiparametric methods to enable modeling of non-linear association [24]. Additionally, we tested the associations between CRP and DBP, pulse pressure (PP), and mean arterial pressure (MAP) using the same model. The same methods were also applied to the non-RA outpatient population and NHANES.

In the RA outpatient population, we performed a longitudinal study examining the association between the 
changes in inflammation and changes in BP. In RA, having a high level of inflammation is typically a temporary state due to an RA flare or inadequate response to treatment. Thus, subjects with RA routinely have large changes in CRP in the course of routine care, providing an opportunity to study the association between longitudinal changes in inflammation and BP. For this study, we focused on patients with RA who had an increase or decrease in CRP by $\geq 10 \mathrm{mg} / \mathrm{L}$, which is considered a significant change in inflammation $[25,26]$. We applied linear mixed effect models to account for correlation between repeated measures within subjects to examine the associations between changes in CRP and changes in SBP. We defined baseline as the day of their first sameday CRP and BP measurements during the study period. Model 1 was adjusted for baseline CRP and baseline SBP. Model 2 was additionally adjusted for age at baseline (continuous), gender, race (non-Hispanic white/nonHispanic black/other races), anti-hypertensive medication use at baseline (yes/no), and statin use at baseline (yes/no). Model 3 was further adjusted for common RA treatments at baseline - TNFi, MTX, and leflunomide, which has a known association with elevated BP [27]. The potential effect of corticosteroids was also assessed by further adjusting the model for corticosteroid use. The same methods were applied to examine the associations between change in CRP and change in DBP, PP, and MAP.

Sensitivity analysis was performed by trimming extreme measurements of CRP $(<0.5 \%$ and $>99.5 \%)$ in both cohorts to prevent the strong influence of a small number of extreme values. Covariate data including age, gender, race, baseline anti-hypertensive medication use, and baseline statin use were extracted in both outpatient populations and NHANES.

To determine potential causes of elevated CRP in the outpatient population, we randomly selected 50 subjects with CRP in the highest decile. We reviewed medical records on or near the date of the elevated CRP and annotated the cause of the elevated CRP as attributed by the treating physician.

For all statistical analyses, a two-sided $P$ value $<0.05$ was considered to be statistically significant. All data analyses were performed using SAS 9.4 (SAS Institute Inc., Cary, NC, USA) and R version 3.2.2 (R Development Core Team) statistical packages. This study protocol was approved by the Partners Healthcare Institutional Review Board.

\section{Results}

A total of 24,325 subjects were included in the outpatient population, of whom 1811 had RA (RA outpatient population) and 22,514 did not (non-RA outpatient population). We studied 5561 subjects from the NHANES cohort (Table 1). Subjects with RA were generally older with mean age 60.4 years, compared to 54.0 years in the non-RA outpatient population and 47.9 years in NHANES. The median CRP was $3.4 \mathrm{mg} / \mathrm{L}$ (range $0.20-126.90 \mathrm{mg} / \mathrm{L}$ ) in the RA outpatient population, $2.2 \mathrm{mg} / \mathrm{L}$ (range $0.10-416.20 \mathrm{mg} / \mathrm{L}$ ) in the non-RA outpatient population, and $0.18 \mathrm{mg} / \mathrm{L}$

Table 1 Clinical characteristic of subjects in the RA outpatient population, non-RA outpatient population and the general population (NHANES)

\begin{tabular}{|c|c|c|c|}
\hline \multirow[t]{2}{*}{ Characteristic } & \multicolumn{2}{|c|}{$\begin{array}{l}\text { Outpatient population } \\
N=24,325\end{array}$} & \multirow[t]{2}{*}{$\begin{array}{l}\text { NHANES* } \\
N=5561\end{array}$} \\
\hline & $\begin{array}{l}\mathrm{RA} \\
\mathrm{N}=1811\end{array}$ & $\begin{array}{l}\text { Non-RA } \\
\mathrm{N}=22,514\end{array}$ & \\
\hline Age, years, mean (SD) & $60.39(13.97)$ & $54.00(15.55)$ & $47.88(18.49)$ \\
\hline Female (\%) & 80.18 & 61.03 & 50.46 \\
\hline \multicolumn{4}{|l|}{ Ethnicity (\%) } \\
\hline Non-Hispanic white & 80.51 & 80.40 & 48.48 \\
\hline Non-Hispanic black & 5.63 & 5.46 & 16.90 \\
\hline Others & 13.86 & 14.14 & 34.62 \\
\hline Anti-hypertensive medication use (\%) & 23.47 & 25.38 & 30.30 \\
\hline Statin medication use (\%) & 10.38 & 12.92 & 17.59 \\
\hline CRP, mg/L, median (IQR) & $3.40(1.40,9.00)$ & $2.20(0.90,5.80)$ & $0.18(0.07,0.43)$ \\
\hline $\mathrm{SBP}, \mathrm{mmHg}$, mean (SD) & $129.92(17.12)$ & $126.48(16.81)$ & $122.14(18.26)$ \\
\hline $\mathrm{DBP}, \mathrm{mmHg}$, mean (SD) & $75.62(11.47)$ & $76.07(15.66)$ & $69.30(11.92)$ \\
\hline $\mathrm{PP}, \mathrm{mmHg}$, mean (SD) & $54.30(14.57)$ & $50.41(17.94)$ & $52.83(17.51)$ \\
\hline MAP, mmHg, mean (SD) & $93.72(11.76)$ & $92.87(13.65)$ & $86.91(11.74)$ \\
\hline
\end{tabular}

RA rheumatoid arthritis, NHANES National Health and Nutrition Examination Survey, CRP C-reactive protein, $S B P$ systolic blood pressure, $D B P$ diastolic blood pressure, $P P$ pulse pressure, MAP mean arterial pressure 
(range 0.01 to $18.01 \mathrm{mg} / \mathrm{L}$ ) in NHANES. Additional characteristics for the RA population include $51.49 \%$ anticyclic citrullinated peptide (anti-CCP) positive, $41.25 \%$ on MTX, and 22.25\% on TNFi.

\section{Associations between CRP and BP in the RA and non-RA outpatient populations and NHANES}

The ranges of CRP were $0.20-126.90 \mathrm{mg} / \mathrm{L}$ in the RA outpatient population, $0.10-416.20 \mathrm{mg} / \mathrm{L}$ in the non-RA outpatient population, and $0.01-18.01 \mathrm{mg} / \mathrm{L}$ in NHANES. In both the RA and non-RA outpatient populations, we observed an inverse U-shaped association between CRP and SBP (Figs. 1 and 2).

In the RA outpatient population, a positive association was observed between CRP and SBP in subjects with $\mathrm{CRP}<5.94 \mathrm{mg} / \mathrm{L}$. We observed an inverse relationship between CRP and SBP at CRP $\geq 5.94 \mathrm{mg} / \mathrm{L}$ (Fig. 1). A similar relationship was observed between CRP and SBP in the non-RA outpatient population. A positive relationship was observed between CRP and SBP until CRP levels reached $8.39 \mathrm{mg} / \mathrm{L}$. There was an inverse relationship between CRP and SBP at CRP $\geq 8.39 \mathrm{mg} / \mathrm{L}$. In comparison, within NHANES, we observed a positive association between CRP and SBP.

The relationships between CRP and PP also differed in the RA and non-RA outpatient populations compared to NHANES, whereby there was an inverse relationship between CRP and PP after a threshold level of

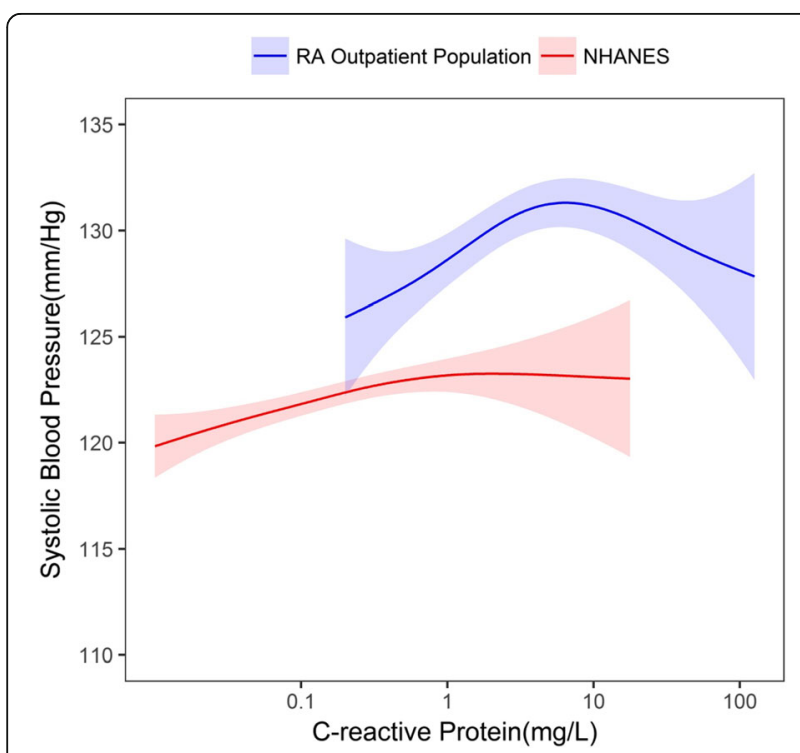

Fig. 1 The relationship between C-reactive protein levels (CRP) and systolic blood pressure with 95\% confidence intervals, in the rheumatoid arthritis (RA) outpatient population and the general population (National Health and Nutrition Examination Survey (NHANES)). RA outpatient population CRP range $0.20-126.90 \mathrm{mg} / \mathrm{L}$; NHANES CRP range $0.01-18.01 \mathrm{mg} / \mathrm{L}$

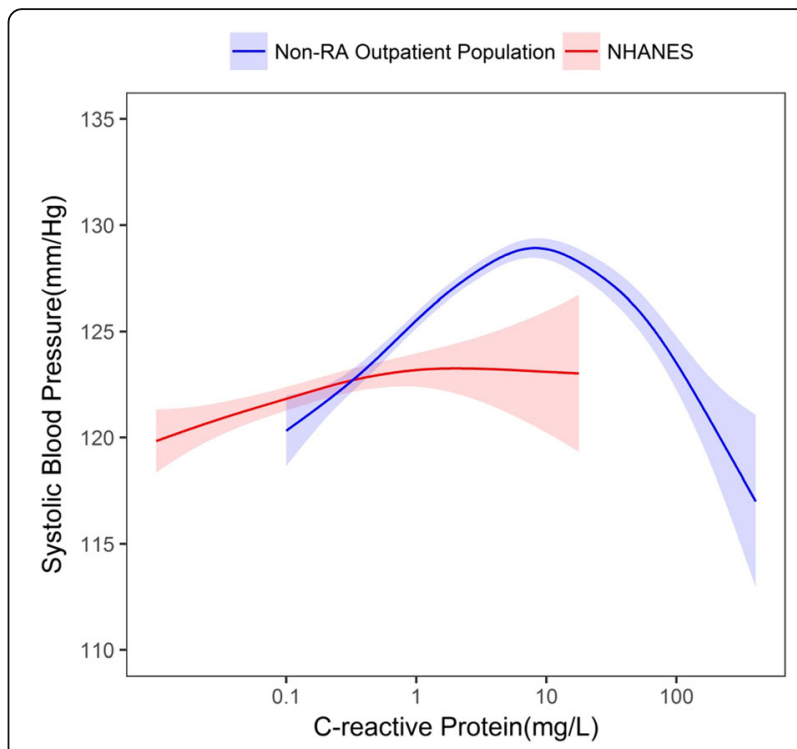

Fig. 2 The relationship between C-reactive protein (CRP) levels and systolic blood pressure with 95\% confidence intervals, in the non-rheumatoid arthritis (RA) outpatient population and the general population (National Health and Nutrition Examination Survey (NHANES)). Non-RA outpatient population CRP range $0.10-416.20 \mathrm{mg} / \mathrm{L}$; NHANES $0.01-18.01 \mathrm{mg} / \mathrm{L}$

CRP was reached (Additional file 1: Figure S1B and Additional file 2: Figure S2B). The relationships between CRP and DBP and MAP were qualitatively more similar across the RA, non-RA and the general population cohorts (Additional file 1: Figure $\mathrm{S} 1 \mathrm{~A}$ and $\mathrm{S} 1 \mathrm{C}$, Additional file 2: Figure S2A and S2C). Findings from the sensitivity analysis with trimming of extreme measurements of CRP were similar to the main analysis (Additional file 3: Figure S3 and Additional file 4: Figure S4).

RA and other inflammatory arthritides (e.g. psoriatic arthritis, gout) comprised the largest percentage of subjects with CRP in the highest decile (34\%), followed by infection (22\%). Connective tissue diseases, including systemic lupus erythematosus, Sjogren's syndrome, and myositis, were attributed by the treating rheumatologist to the elevated CRP in 10\% of cases. Inflammatory bowel disease was attributed as the cause of the elevated CRP in $8 \%$ of cases and the etiology of the elevated CRP could not be determined in $14 \%$ of subjects.

\section{Longitudinal association between CRP and BP in RA}

We identified 355 patients with RA from the RA outpatient population who had CRP changes defined as $\geq 10 \mathrm{mg} / \mathrm{L}$ or $\leq-10 \mathrm{mg} / \mathrm{L}$ at $\geq 2$ consecutive time points between 1 January 2009 and 1 June 2012. The median baseline CRP in this population was 9.7 (25th percentile 3.4, 75th percentile 25.4) $\mathrm{mg} / \mathrm{L}$. The mean SBP was $131.2 \mathrm{mmHg}$ (SD 18.4) and DBP was $75.9 \mathrm{mmHg}$ 
(SD 11.9). Of the 355 subjects with RA, 80.3\% were female and $78.9 \%$ were white. The mean temporal interval between two time points in which CRP and BP were concomitantly recorded was 0.41 year (SD: 0.40 ). At baseline, $27.6 \%$ subjects were on anti-hypertensive medications, 10. $7 \%$ on statin, $38.3 \%$ on MTX, $27.3 \%$ on a TNFi, and $15.2 \%$ on leflunomide.

Among patients with RA with significant inflammation change, as defined by CRP $\geq 10 \mathrm{mg} / \mathrm{L}$, we observed a significant inverse association between the change in CRP and change in BP. Every $10 \mathrm{mg} / \mathrm{L}$ increase in CRP was associated with a $0.38-\mathrm{mmHg}$ reduction in SBP. This relationship remained the same after adjusting for age, gender, race, anti-hypertensive medication, and statin use. As well, this relationship remained the same after additionally adjusting for potent immunomodulators such as TNFi, MTX, and leflunomide (Table 2). The association between CRP and SBP also remained the same after adjusting for corticosteroid use ( $\beta-0.38,95 \% \mathrm{CI}$ $-0.66,-0.10, p=0.007)$. An increase in CRP was also associated with reductions in DBP, PP, and MAP (Additional file 5: Table S1).

\section{Discussion}

In summary, our study corroborates previous reports of a positive linear association between CRP and SBP. However, we found that this relationship was true only in the range of CRP typically observed in the general population. At higher CRP levels, we observed an inverse association between CRP and SBP. This inverse relationship was present not only in RA, but also in the non-RA outpatient population. Thus, previous studies on the association between inflammation and SBP may have shed light on only half the relationship. Studying a broader range of CRP levels in subjects allowed us to fill in information on the relationship between inflammation and BP between the two extremes, "normal" and those with sepsis. Studying data in a large population allowed us to identify this relationship.

Table 2 Association between change in C-reactive protein (CRP) (per $10 \mathrm{mg} / \mathrm{L}$ ) and change in systolic blood pressure (SBP) (per $\mathrm{mmHg}$ ) in patients with rheumatoid arthritis with significant changes in inflammation

\begin{tabular}{lll}
\hline Models* & \multicolumn{2}{l}{ Change in SBP per $10 \mathrm{mg} / \mathrm{L}$ increase in CRP } \\
\cline { 2 - 3 } & Coefficient $(95 \% \mathrm{Cl})$ & $P$ value \\
\hline Model 1 & $-0.38(-0.66,-0.11)$ & 0.007 \\
Model 2 & $-0.38(-0.66,-0.11)$ & 0.007 \\
Model 3 & $-0.38(-0.66,-0.10)$ & 0.007
\end{tabular}

*Model 1, adjusted for baseline CRP level and SBP; model 2, additionally adjusted for age (continuous), gender (male/female), race (non-Hispanic white/ non-Hispanic black/other races), anti-hypertensive medication use (yes/no), and statin medication use (yes/no); model 3, additionally adjusted for tumor necrosis factor inhibitors medication use (yes/no), leflunomide use (yes/no), and methotrexate medication use (yes/no)
Based on the cross-sectional study, a subject with $\mathrm{CRP} \geq 10 \mathrm{mg} / \mathrm{L}$ would lie at the right side of the inverse U-shaped curve in Fig. 1. Based on the cross-sectional data, a reduction in inflammation would be associated with an increase in SBP. Indeed, this relationship was confirmed in the longitudinal analysis, where a reduction in CRP was associated with a modest increase in SBP. The association remained significant after adjusting for potential confounders including age, gender, and common RA treatments.

These findings may explain the absence of association between CRP and the outcome of hypertension in RA in a previous study [28]. The previous study used a binary outcome for hypertension, which would not detect a nonlinear relationship between CRP and BP. Our findings are also consistent with current knowledge on the relationship between sepsis, an extreme form of inflammation, and BP. Uncontrolled inflammation in sepsis is linked with endothelial dysfunction and hypotension [29, 30]. Treatment and resolution of sepsis is associated with normalization of BP. Based on our data, we observed a similar though less severe pattern in subjects with RA, and in non-RA subjects with evidence of inflammation defined as elevated CRP. While there are studies on BP in sepsis, to our knowledge, there were no studies examining subjects in this intermediate group with mild to moderate CRP elevation.

The significance of our findings relates more to population health rather $\mathrm{CV}$ risk management at the individual level. In a recent study using data from the Atherosclerosis Risk in Communities study, investigators found that a 1-mmHg reduction in SBP was associated with substantial reduction in cardiovascular events at the population level [31]. Thus, the modest changes in SBP observed with changes in CRP may influence $\mathrm{CV}$ risk among subjects with inflammatory diseases. Taken in a larger context, the results of this study suggest a similar phenomenon to the lipid paradox in RA [32]. In the lipid paradox, lower lipids have not been associated with lower CV risk. Patients with RA with a reduction in inflammation, which is considered protective against $\mathrm{CV}$ risk, also experience an increase in low-density lipoprotein cholesterol (LDL-C) [10, 33], a marker of increased CV risk. In this study, reduction in inflammation (suggesting lower $\mathrm{CV}$ risk) was associated with modest increases in BP (suggesting higher CV risk). Thus, inflammation may be modifying the relationship between traditional CV risk factors, adding blood pressure to the list of factors already known to be altered in RA, including lipids and insulin resistance [34, 35].

Additionally, we observed that compared to the general population, the RA population on average had higher BP, at any given CRP level. While the mean BP at most CRP levels would not reach the threshold for 
classification as hypertension [36], these modest differences in SBP may also explain the known elevated risk for CVD in RA compared to the general population. The higher SBP in the outpatient population is likely due to a higher prevalence of hypertension in a clinic-based cohort compared to the general population.

The influences of inflammation on traditional $\mathrm{CV}$ risk factors may partially explain the underestimation of $\mathrm{CV}$ risk observed in several studies [37-39]. From the management perspective, this study adds to the current data on the importance of assessing CV risk among subjects with RA and those with other inflammatory diseases, when their disease is well-controlled. Assessing CV risk during active inflammatory disease may lead to measurements of both lipids and blood pressures that are lower than if the patients were in low disease activity or remission.

Limitations of this study include studying only patients who had CRP measured as part of routine care. As CRP is measured when a clinician is concerned about inflammation, the analysis likely includes the majority of patients with any type of inflammatory condition, which was a goal of the study. While CRP is only one of many markers of inflammation, it has been widely adopted for use across multiple conditions and was selected because it is a clinically interpretable test. Additionally, we adjusted for additional factors that may confound the association between CRP and BP, but not all factors were available for inclusion in the models. We examined known major confounders including age, gender, race, and anti-hypertensive and RA treatments.

We note that there are two potential confounders where ascertainment can be suboptimal using EMR data: non-steroidal anti-inflammatory drugs (NSAIDs) and corticosteroids. NSAIDs were not included in our models because the majority of NSAID use is over the counter not requiring a prescription, and so analysis of prescriptions for NSAIDs may be biased [40, 41]. The anticipated effect of NSAID use is elevated CRP, regardless of CRP levels, which would attenuate the association between elevated CRP and lower SBP. Thus, we anticipate that NSAID use would generally bias our findings towards the null. We observed no difference in association between change in CRP and change in SBP after adjusting for corticosteroids.

Another potential concern was differences in treatment among subjects with RA who had increases or decreases in their CRP, explaining the inverse association between CRP and SBP at higher CRP levels. When examining baseline treatments, we observed a similar percentage of biologic disease-modifying anti-rheumatic drug use among subjects who experienced a decrease in CRP (12.4\%) compared to that among subjects who experienced an increase in CRP (12.5\%). Other potential confounders not measured were the duration and doses of therapy. Last, the study population was selected from a tertiary care center and may not be generalizable to other community-based centers.

While identifying mechanisms for our findings is beyond the scope of this study, one potential mediator of this association is endothelial function, which plays an important role in vasomotor function and regulation of BP [42]. Patients with RA have increased arterial stiffness, which is attributed to endothelial dysfunction [43]. Treatment with the potent RA anti-inflammatory agent, $\mathrm{TNFi}$, is associated with a significant reduction in disease activity and significant improvements in endothelial dependent and independent vasodilation of the brachial artery in patients with RA [44]. There is also evidence to suggest that endothelial dysfunction is influenced by other inflammatory cytokines in addition to TNF [45]. Together the data suggest that inflammation may impact endothelial function, vasomotor function, and regulation of BP. In line with these findings, we observed an inverse U-shaped association between CRP and PP, where PP is considered closely associated with endothelial function [46].

\section{Conclusions}

In conclusion, our study suggests that CRP, used as a marker of inflammation, has a biphasic relationship with SBP when examining the relationship across the range of CRP levels observed in RA and in the outpatient setting. At lower levels of inflammation typically observed in the general population, an increase in CRP is associated with an increase in SBP. In RA and other states where a patient has elevated levels of inflammation, the relationship changes, such that CRP is associated with a decrease in SBP. When inflammation is mitigated, the relationship normalizes such that BP may increase as inflammation decreases, until general population levels of CRP are reached. While the changes in SBP were modest, they highlight a new relationship between CRP and BP not characterized previously. From the population health perspective, modest changes in SBP can have a substantial impact on CV risk. The pathways mediating these changes remains to be seen, however there is evidence to suggest endothelial function may play an important role. These data suggest a need to reevaluate our current approach to interpreting $\mathrm{BP}$ and $\mathrm{CV}$ risk in the setting of active inflammation in RA and other conditions, and the need for a better understanding of the pathways linking inflammation and BP regulation. Future studies in cohorts with detailed data on both inflammation and $\mathrm{CV}$ risk factors and outcomes are needed to determine the clinical significance of changes in inflammation on blood pressure and overall CV risk. 


\section{Additional files}

Additional file 1: Figure S1. The relationship between $\mathrm{C}$-reactive protein levels (CRP) and diastolic blood pressure (A), pulse pressure (B), and mean arterial pressure (C) with 95\% confidence intervals, in the RA outpatient population and general population (NHANES). RA, rheumatoid arthritis; NHANES, National Health and Nutrition Examination Survey. (PDF 1475 kb)

Additional file 2: Figure S2. The relationship between C-reactive protein levels (CRP) and diastolic blood pressure (A), pulse pressure (B), and mean arterial pressure (C) with 95\% confidence intervals, in the non-RA outpatient population and the general population (NHANES). RA, rheumatoid arthritis; NHANES, National Health and Nutrition Examination Survey. (PDF 1361 kb)

Additional file 3: Figure S3. The relationship between C-reactive protein levels (CRP) and systolic blood pressure with 95\% confidence intervals, in the RA outpatient population and the general population (NHANES) with trimming of extreme measurements of CRP $(<0.5 \%$ and $>99.5 \%)$. RA outpatient population CRP range $0.20-92.40 \mathrm{mg} / \mathrm{L}$; NHANES CRP range 0.02-4.22 mg/L. RA, rheumatoid arthritis; NHANES, National Health and Nutrition Examination Survey. (PDF 476 kb)

Additional file 4: Figure S4. The relationship between C-reactive protein levels (CRP) and systolic blood pressure with 95\% confidence intervals, in the non-RA outpatient population and general population (NHANES) with trimming of extreme measurements of CRP ( $<0.5 \%$ and $>99.5 \%)$. Non-RA outpatient population CRP range 0.10-142.20 mg/L; NHANES CRP range 0.02-4.22 mg/L. RA, rheumatoid arthritis; NHANES, National Health and Nutrition Examination Survey. (PDF 471 kb)

Additional file 5: Table S1. Association between change in C-reactive protein (CRP) (per $10 \mathrm{mg} / \mathrm{L}$ ) and change in diastolic blood pressure (DBP), pulse pressure (PP), and mean arterial pressure (MAP) (per mmHg) in patients with rheumatoid arthritis with significant changes in inflammation. (DOCX $17 \mathrm{~kb})$

\section{Abbreviations}

BP: Blood pressure; BWH: Brigham and Women's Hospital; CRP: C-reactive protein; CV: Cardiovascular; CVD: Cardiovascular disease; DBP: Diastolic blood pressure; EMR: Electronic medical record; MAP: Mean arterial pressure; MGH: Massachusetts General Hospital; MTX: Methotrexate; NHANES: National Health and Nutrition Examination Survey; NSAIDs: Non-steroidal anti-inflammatory drugs; PP: Pulse pressure; RA: Rheumatoid arthritis; RPDR: Research Patient Data Repository; TNFi: Tumor necrosis factor inhibitors

\section{Acknowledgements}

We would like to acknowledge ChihChin Liu, Senior Biostatistician, Alkermes Pharmaceutical, who participated in the initial development of the research question during her time at Brigham and Women's Hospital.

\section{Funding}

This study was supported by the grants R01 HL127118, P30 AR2072577, R01 EB014947, U54 LM008748, U01 HG008685, and U54 HG007963, and from the National Institutes of Health, PCORI 282364.5077585.0007 from the PatientCentered Outcomes Research Institute, and a grant from the Harold and Duval Bowen Fund. The content is solely the responsibility of the authors and does not necessarily represent the official views of the National Institutes of Health.

\section{Availability of data and materials}

General population data analyzed during the current study are available in the NHANES repository https://www.cdc.gov/nchs/nhanes/. Outpatient population data that support the findings of this study are available from the Partners RPDR, but restrictions apply to the availability of these data. Data are, however, available from the authors upon reasonable request and with permission from the RPDR.

\section{Authors' contributions}

$\mathrm{ZY}, \mathrm{SK}, \mathrm{RD}, \mathrm{DH}$, and $\mathrm{KL}$ contributed to study conception and design; ZY, KV, $\mathrm{JH}, \mathrm{SM}$, and $\mathrm{KL}$ contributed to data acquisition and analysis; $\mathrm{ZY}, \mathrm{SK}, \mathrm{RD}, \mathrm{JH}$, $\mathrm{DH}$, and $\mathrm{KL}$ contributed to interpretation of data; $Z Y$ and $K P L$ had primary responsibility for final content; all authors contributed to critical revision and approved the final manuscript.

\section{Ethics approval and consent to participate}

Our study protocol was approved by the Partners Healthcare Institutional Review Board.

\section{Competing interests}

All authors have completed the Unified Competing Interest form and declare the following interests: SCK receives research grants to Brigham and Women's Hospital from Pfizer, Lilly, Genentech, AstraZeneca, and Bristol-Myers Squibb. DHS receives research grants to Brigham and Women's Hospital from Amgen, Lilly, Pfizer, AstraZeneca, Bristol-Myers Squibb, Genentech, and Corrona. He serves in an unpaid capacity on a Pfizer-sponsored trial on an unrelated topic. He receives royalties from UpToDate on unrelated topics. No other authors report any disclosures.

\section{Publisher's Note}

Springer Nature remains neutral with regard to jurisdictional claims in published maps and institutional affiliations.

\section{Author details}

${ }^{1}$ Department of Epidemiology, Johns Hopkins Bloomberg School of Public Health, Baltimore, MD, USA. ${ }^{2}$ Department of Biostatistics, Johns Hopkins Bloomberg School of Public Health, Baltimore, MD, USA. ${ }^{3}$ Division of Rheumatology, Allergy and Immunology, Brigham and Women's Hospital, Boston, MA 02115, USA. ${ }^{4}$ Division of Pharmacoepidemiology and Pharmacoeconomics, Brigham and Women's Hospital, Boston, MA, USA. ${ }^{5}$ Research Computing, Partners HealthCare, Charlestown, MA, USA. ${ }^{6}$ Laboratory of Computer Science, Massachusetts General Hospital, Boston, MA, USA. 'Department of Biomedical Informatics, Harvard Medical School, Boston, MA, USA.

Received: 2 December 2017 Accepted: 18 April 2018 Published online: 01 June 2018

\section{References}

1. Bautista LE, Vera LM, Arenas IA, Gamarra G. Independent association between inflammatory markers (C-reactive protein, interleukin-6, and TNFalpha) and essential hypertension. J Hum Hypertens. 2005;19(2):149-54.

2. Sesso HD, Buring JE, Rifai N, Blake GJ, Gaziano JM, Ridker PM. C-reactive protein and the risk of developing hypertension. JAMA. 2003;290(22): 2945-51.

3. lannaccone CK, Lee YC, Cui J, Frits ML, Glass RJ, Plenge RM, Solomon DH, Weinblatt ME, Shadick NA. Using genetic and clinical data to understand response to disease-modifying anti-rheumatic drug therapy: data from the Brigham and Women's Hospital Rheumatoid Arthritis Sequential Study. Rheumatology (Oxford). 2011:50(1):40-6.

4. Ridker PM, Buring JE, Rifai N, Cook NR. Development and validation of improved algorithms for the assessment of global cardiovascular risk in women: the Reynolds Risk Score. JAMA. 2007;297(6):611-9.

5. Avina-Zubieta JA, Thomas J, Sadatsafavi M, Lehman AJ, Lacaille D. Risk of incident cardiovascular events in patients with rheumatoid arthritis: a metaanalysis of observational studies. Ann Rheum Dis. 2012;71(9):1524-9.

6. Gabriel S. Heart disease in rheumatoid arthritis: changing the paradigm of systemic inflammatory disorders. J Rheumatol. 2007;34(1):220-3.

7. Solomon DH, Karlson EW, Rimm EB, Cannuscio CC, Mandl LA, Manson JE, Stampfer MJ, Curhan GC. Cardiovascular morbidity and mortality in women diagnosed with rheumatoid arthritis. Circulation. 2003;107(9):1303-7.

8. Navarro-Millan I, Yang S, DuVall SL, Chen L, Baddley J, Cannon GW, Delzell ES, Zhang J, Safford MM, Patkar NM, et al. Association of hyperlipidaemia, inflammation and serological status and coronary heart disease among patients with rheumatoid arthritis: data from the National Veterans Health Administration. Ann Rheum Dis. 2015;75(2):341-7.

9. Charles-Schoeman C, Fleischmann R, Davignon J, Schwartz H, Turner SM, Beysen C, Milad M, Hellerstein MK, Luo Z, Kaplan IV, et al. Potential mechanisms leading to the abnormal lipid profile in patients with rheumatoid arthritis versus healthy volunteers and reversal by tofacitinib. Arthritis Rheumatol. 2015;67(3):616-25.

10. Liao KP, Playford MP, Frits M, Coblyn JS, lannaccone C, Weinblatt ME, Shadick NS, Mehta NN. The association between reduction in inflammation and changes in lipoprotein levels and HDL cholesterol efflux capacity in rheumatoid arthritis. J Am Heart Assoc. 2015;4(2):e001588. 
11. Robertson J, Porter D, Sattar N, Packard CJ, Caslake M, Mclnnes I, McCarey D. Interleukin-6 blockade raises LDL via reduced catabolism rather than via increased synthesis: a cytokine-specific mechanism for cholesterol changes in rheumatoid arthritis. Ann Rheum Dis. 2017;76(11):1949-52.

12. del Rincon I, Polak JF, O'Leary DH, Battafarano DF, Erikson JM, Restrepo JF, Molina E, Escalante A. Systemic inflammation and cardiovascular risk factors predict rapid progression of atherosclerosis in rheumatoid arthritis. Ann Rheum Dis. 2015;74(6):1118-23.

13. Wright JT Jr, Williamson JD, Whelton PK, Snyder JK, Sink KM, Rocco MV, Reboussin DM, Rahman M, Oparil S, Lewis CE, et al. A randomized trial of intensive versus standard blood-pressure control. N Engl J Med. 2015; 373(22):2103-16.

14. Peters SA, Huxley RR, Woodward M. Comparison of the sex-specific associations between systolic blood pressure and the risk of cardiovascular disease: a systematic review and meta-analysis of 124 cohort studies, including 1.2 million individuals. Stroke. 2013;44(9):2394-401.

15. Ettehad D, Emdin CA, Kiran A, Anderson SG, Callender T, Emberson J, Chalmers J, Rodgers A, Rahimi K. Blood pressure lowering for prevention of cardiovascular disease and death: a systematic review and meta-analysis. Lancet. 2016;387(10022):957-67.

16. Kuller LH, Tracy RP, Shaten J, Meilahn EN. Relation of C-reactive protein and coronary heart disease in the MRFIT nested case-control study. Multiple Risk Factor Intervention Trial. Am J Epidemiol. 1996;144(6):537-47.

17. McQuillan GM, McLean JE, Chiappa M, Lukacs SL. National Health and Nutrition Examination Survey biospecimen program: NHANES III (19881994) and NHANES 1999-2014. National Center for Health Statistics. Vita Health Stat. 2015;2(170).

18. Nalichowski R, Keogh D, Chueh HC, Murphy SN. Calculating the benefits of a research patient data repository. AMIA Annu Symp Proc. 2006;1044.

19. Carroll RJ, Thompson WK, Eyler AE, Mandelin AM, Cai T, Zink RM, Pacheco JA, Boomershine CS, Lasko TA, Xu H, et al. Portability of an algorithm to identify rheumatoid arthritis in electronic health records. J Am Med Inform Assoc. 2012;19(e1):e162-9.

20. Liao KP, Cai T, Gainer V, Goryachev S, Zeng-treitler Q, Raychaudhuri S, Szolovits P, Churchill S, Murphy S, Kohane I, et al. Electronic medical records for discovery research in rheumatoid arthritis. Arthritis Care Res. 2010;62(8): $1120-7$

21. Ong KL, Allison MA, Cheung BM, Wu BJ, Barter PJ, Rye KA. Trends in Creactive protein levels in US adults from 1999 to 2010. Am J Epidemiol. 2013;177(12):1430-42.

22. Yoon SS, Fryar CD, Carroll MD. Hypertension prevalence and control among adults: United States, 2011- 2014. NCHS data brief, no 220. Hyattsville, MD: National Center for Health Statistics; 2015

23. Whicher JT, Ritchie RF, Johnson AM, Baudner S, Bienvenu J, Blirup-Jensen S, Carlstrom A, Dati F, Ward AM, Svendsen PJ. New international reference preparation for proteins in human serum (RPPHS). Clin Chem. 1994;40(6): 934-8.

24. Hastie TJ, Tibshirani RJ. Generalized additive models. New York: Chapman and Hall; 1990

25. Myers GL, Rifai N, Tracy RP, Roberts WL, Alexander RW, Biasucci LM, Catravas JD, Cole TG, Cooper GR, Khan BV, et al. CDC/AHA Workshop on Markers of Inflammation and Cardiovascular Disease: Application to Clinical and Public Health Practice: report from the laboratory science discussion group. Circulation. 2004;110(25):e545-9.

26. Kushner I, Rzewnicki D, Samols D. What does minor elevation of C-reactive protein signify? Am J Med. 2006;119(2):166 e117-28.

27. Rozman B, Praprotnik S, Logar D, Tomsic M, Hojnik M, Kos-Golja M, Accetto R, Dolenc P. Leflunomide and hypertension. Ann Rheum Dis. 2002;61 (6):567-9.

28. Manavathongchai S, Bian A, Rho YH, Oeser A, Solus JF, Gebretsadik T, Shintani A, Stein CM. Inflammation and hypertension in rheumatoid arthritis. J Rheumatol. 2013;40(11):1806-11.

29. Singer M, Deutschman CS, Seymour CW, Shankar-Hari M, Annane D, Bauer M, Bellomo R, Bernard GR, Chiche JD, Coopersmith CM, et al. The Third international consensus definitions for sepsis and septic shock (Sepsis-3). JAMA 2016;315(8):801-10.

30. Schouten M, Wiersinga WJ, Levi M, van der Poll T. Inflammation, endothelium, and coagulation in sepsis. J Leukoc Biol. 2008;83(3):536-45.

31. Hardy ST, Loehr LR, Butler KR, Chakladar S, Chang PP, Folsom AR, Heiss G, MacLehose RF, Matsushita K, Avery CL. Reducing the blood pressure-related burden of cardiovascular disease: impact of achievable improvements in blood pressure prevention and control. J Am Heart Assoc. 2015;4(10):e002276.
32. Myasoedova E, Crowson CS, Kremers HM, Roger VL, Fitz-Gibbon PD, Therneau TM, Gabriel SE. Lipid paradox in rheumatoid arthritis: the impact of serum lipid measures and systemic inflammation on the risk of cardiovascular disease. Ann Rheum Dis. 2011;70(3):482-7.

33. Navarro-Millan I, Charles-Schoeman C, Yang S, Bathon JM, Bridges SL Jr, Chen L, Cofield SS, Dell'Italia LJ, Moreland LW, O'Dell JR, et al. Changes in lipoproteins associated with methotrexate or combination therapy in early rheumatoid arthritis: results from the treatment of early rheumatoid arthritis trial. Arthritis Rheum. 2013;65(6):1430-8.

34. Dessein $\mathrm{PH}$, Joffe BI. Insulin resistance and impaired beta cell function in rheumatoid arthritis. Arthritis Rheum. 2006:54(9):2765-75.

35. Chung CP, Oeser A, Solus JF, Gebretsadik T, Shintani A, Avalos I, Sokka T, Raggi $P$, Pincus T, Stein CM. Inflammation-associated insulin resistance: differential effects in rheumatoid arthritis and systemic lupus erythematosus define potential mechanisms. Arthritis Rheum. 2008;58(7):2105-12

36. Whelton PK, Carey RM, Aronow WS, Casey DE Jr, Collins KJ, Dennison Himmelfarb C, DePalma SM, Gidding S, Jamerson KA, Jones DW, et al. 2017 ACC/AHA/AAPA/ABC/ACPM/AGS/APhA/ASH/ASPC/NMA/PCNA guideline for the prevention, detection, evaluation, and management of high blood pressure in adults: executive summary: a report of the American College of Cardiology/American Heart Association Task Force on clinical practice guidelines. Hypertension. 2017. [Epub ahead of print]

37. Crowson CS, Matteson EL, Roger VL, Therneau TM, Gabriel SE. Usefulness of risk scores to estimate the risk of cardiovascular disease in patients with rheumatoid arthritis. Am J Cardiol. 2012;110(3):420-4.

38. Kawai VK, Chung CP, Solus JF, Oeser A, Raggi P, Stein CM. The ability of the 2013 American College of Cardiology/American Heart Association cardiovascular risk score to identify rheumatoid arthritis patients with high coronary artery calcification scores. Arthritis Rheumatol. 2015;67(2):381-5.

39. Arts EE, Popa C, Den Broeder AA, Semb AG, Toms T, Kitas GD, van Riel PL, Fransen J. Performance of four current risk algorithms in predicting cardiovascular events in patients with early rheumatoid arthritis. Ann Rheum Dis. 2015;74(4):668-74.

40. Duong M, Salvo F, Pariente A, Abouelfath A, Lassalle R, Droz C, Blin P, Moore N. Usage patterns of 'over-the-counter' vs. prescription-strength nonsteroidal antiinflammatory drugs in France. Br J Clin Pharmacol. 2014;77(5):887-95.

41. Adams RJ, Appleton SL, Gill TK, Taylor AW, Wilson DH, Hill CL. Cause for concern in the use of non-steroidal anti-inflammatory medications in the community-a population-based study. BMC Fam Pract. 2011;12:70.

42. Dharmashankar K, Widlansky ME. Vascular endothelial function and hypertension: insights and directions. Curr Hypertens Rep. 2010;12(6):448-55.

43. Klocke R, Cockcroft JR, Taylor GJ, Hall IR, Blake DR. Arterial stiffness and central blood pressure, as determined by pulse wave analysis, in rheumatoid arthritis. Ann Rheum Dis. 2003;62(5):414-8.

44. Hurlimann D, Forster A, Noll G, Enseleit F, Chenevard R, Distler O, Bechir M, Spieker LE, Neidhart M, Michel BA, et al. Anti-tumor necrosis factor-alpha treatment improves endothelial function in patients with rheumatoid arthritis. Circulation. 2002:106(17):2184-7.

45. Karbach S, Croxford AL, Oelze M, Schuler R, Minwegen D, Wegner J, Koukes L, Yogev N, Nikolaev A, Reissig S, et al. Interleukin 17 drives vascular inflammation, endothelial dysfunction, and arterial hypertension in psoriasislike skin disease. Arterioscler Thromb Vasc Biol. 2014;34(12):2658-68.

46. Beigel R, Dvir D, Arbel Y, Shechter A, Feinberg MS, Shechter M. Pulse pressure is a predictor of vascular endothelial function in middle-aged subjects with no apparent heart disease. Vasc Med. 2010;15(4):299-305.

\section{Ready to submit your research? Choose BMC and benefit from:}

- fast, convenient online submission

- thorough peer review by experienced researchers in your field

- rapid publication on acceptance

- support for research data, including large and complex data types

- gold Open Access which fosters wider collaboration and increased citations

- maximum visibility for your research: over $100 \mathrm{M}$ website views per year

At BMC, research is always in progress.

Learn more biomedcentral.com/submissions 